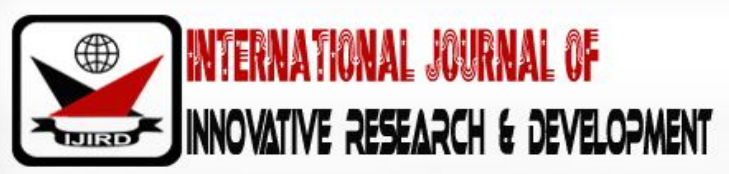

ISSN 2278 - 0211 (Online)

\section{A Model for Estimation of Vesico Vaginal Fistula in Kebbi State, Nigeria}

\author{
A.Ahmed \\ Reader in Statistics, Department of Mathematical Sciences, Abuakar Tafawa Balewa University, Nigeria \\ A.Z.Abubakar \\ Postgraduate Student, Department of Mathematical Sciences, Abuakar Tafawa Balewa University, Nigeria \\ U.F.Abbas \\ Chief Lecturer in Statistics, Department of Mathematics, Fedral Polytechnic, Nigeria
}

\begin{abstract}
:
This paper examined the monthly reported cases of Vesico Vaginal Fistula (VVF) in Kebbi State, Nigeria between the period of 2009-2014 using Box and Jenkins approach. The result from the estimation of parameters of the model showed that ARIMA $(1,1,1)$ is the best model for the data i.e. is appropriate. The initial test statistic value for ADF was -4.2050 which shows that the series has unit root, the KPSS test statistic was 0.839 , and however after the transformation by taken the first differencing the series become stationary. The test statistic for portmanteau was 11.8092 which shows there is absent of serial correlation and ARCH-LM test statistic was 2.9973 shows that the series has no ARCH-LM effect is present. Therefore ARIMA $(1,1,1)$ model was fit the data, (has verify the model is strength). The forecast showed that the menace of VVF is increase in the next 24 months. This study recommended however, to help eradicate the problem in Kebbi State, that the government shall provide obstetric care Centre's most especially in the rural areas, age of marriage no doubt affects pregnancy and also husbands shall allow and encourage their wives to visit hospital during pregnancy period.
\end{abstract}

Keywords: VVF, ARIMA, box-Jenkins approach, ACF, PACF, AIC, SBC and forecast

\section{Introduction}

Kebbi is a state in north-western Nigeria with its capital at BirninKebbi. The state was created out of a part of Sokoto State in 1991. Kebbi State is bordered by Sokoto State, Niger State, Zamfara State, Dosso Region in the Republic of Niger and the nation of Benin. It has a total area of $36,800 \mathrm{~km}^{2}$. With a latitude, 12.4539 , and longitude, 4.1975 respectively, and has a population of 3,238,628 according to the 2006 census. The major local language is Hausa, although the main ethnic groups are Hausa, Fulani, Dakarkari, Kambarawa, Gumbawa and a handful of Zabarmawa. The people are largely Muslims, with a few Christians and some adherents to traditional belief.

Kebbi is traditionally considered by Sarki mythology as the homeland of the Banzabakwai states and Hausa Kingdoms. According to recent research based on local oral traditions, king lists and on the Kebbi chronicle, the state of Kebbi was founded towards 600 BCE by refugees of the Assyrian empire conquered by Babylonian and Median forces in 612 BCE. A major local event was the conquest by Songhai in the second half of the fifteenth century CE.

Vesico vaginal fistula (V.V.F). The term "Vesico" according to the medical profession is called urinary bladder. Vesico vaginal fistula is the abnormal connection between the urinary tract and the vaginal such that there is uncontrollable leakage of urine into the vaginal tract. According to Villey V.J (2006), "VVF is an abnormal communication between the urinary bladder and vaginal that results in the continuous involuntary discharge of urine into the vault" several literatures reveal that the condition has many causes with variation depending on the social and educational status of people. VVF also, is one of the worst associated with delivery. It is an abnormal opening of the vaginal wall to the bladder or rectum or both at the same time, that results in the leakage of urine (VVF) or fasces (Recto vaginal fistula, RVF) or both; VVF and RVF are serious health problems in the development world including Nigeria where it contributes greatly to the country's unacceptable higher maternal mortality (Murphy; 1980 Harrison 1989; kaburuk 1990; Tanko 1994; Chanrasia 2006).

The main causes of VWF in over 85\% of cases is in obstructed labour (prolong labour) necrosis is the cutting through the wall of the mother's abdomen before she can deliver a child (kaburuk 1990, Disk and Armaya'u 1993, WHO 1994; 1997; 1999; 2000). The Minister of women Affairs and social Development disclosed that Nigeria has the highest incidences of 
VVF in the world that with an estimated 40,000 to 800,000 cases with 20,000 new cases added each year. Other cases of VVF in Nigeria are as a result of early girl marriage. Early marriage in many instances leads to the withdrawal of girls from school and thrusts upon them marital and reproductive responsibility for which they are neither physically nor mentally mature to carry out.

\section{Materials and Method}

\subsection{Model Building}

A time series model building is a selection of the appropriate model for the data using Box -Jenkins procedures; the three primary stages in building a Box- Jenkins time series are: Model identification, Model estimation and Diagnostic Checking.

The identification stage is most important and also most difficult. It consists to determine the adequate model for ARIMA (Autoregressive Integrative moving Average), the most general is the Box- Jenkins model which includes difference operators, seasonal autocorrelation and partial autocorrelation. The first step in deploying a Box- Jenkins model is to determine if the series is stationary and if there is any significant seasonality that needs to be modeled. Dickey D.A (1979), in this estimation stage said parameters are estimated for adequate model. The parameters of ARIMA ( $p$ d q) model selected can be estimated consistently by least square or Maximum likelihood Estimates (M.L.E). The estimation of the parameters used in the forecasting stage is to calculate new values of the series and the confidence intervals for those predicted values.

Once an appropriate model had been entertained and its parameters estimated, the Box-Jenkins methodology require examining the residuals of the actual values minus those estimated through the model. If such residuals are random, it is assumed that the model is appropriate, if not another model is entertained.

\subsection{Augmented Dickey Fuller (ADF) Test}

The ADF regression equation due to dickey and fuller (1984). ADF test stationary has been developed in the same manner to check the stationary of the series, in order to make inferences in time series, there must be stationary.

The regression model for the test is given by

$\Delta y_{\mathrm{t}}=\mu_{o}+\mu_{1} t+\varnothing y_{\mathrm{t}-1}+\sum_{j=1}^{p} \alpha j \Delta y_{t}+\varepsilon_{t} \cdots$

Where $t=\mathrm{p}+1, \mathrm{p}+2$ T.

Where $\mu_{o}$ the intercept is $\mu_{1} t$ represents the trend in case it is present, is the coefficient of the legged depended variable. $\Delta y_{\mathrm{t}}$. $\mathrm{j}$ with coefficients $\mathrm{O}_{\mathrm{j}}$ is added to account for serial correlation in the residuals.

The null hypothesis $\mathrm{H}_{0}: \quad=0$ is that the series has unit root while the alternative hypothesis $\mathrm{H}_{1}: \quad \neq \mathbf{0}$

The teat Statistic is given by $\mathrm{ADF}=\frac{\varnothing}{\operatorname{SE}(\widehat{\varnothing})} \ldots$

\subsection{KPSSTest}

Kwiatkowski, Philips, Schmidt P. and Shin (1992) proposed a test of the null hypothesis for an observable series is the trend stationary (Stationary around a deterministic trend). The integration properties of $a$ series $y_{\mathrm{t}}$ may also be investigated by testing the null hypothesis that the series is stationary against a unit root. Assuming no linear trend term, the data generating the process is given as: -

$y_{\mathrm{t}}=X_{\mathrm{t}}+\mathrm{Z}_{\mathrm{t}} \ldots$

Where $\mathcal{X}_{\mathrm{t}}$ is a random walk, $\mathcal{X}_{\mathrm{t}}=\mathcal{X}_{\mathrm{t}-1}+\mathrm{V}_{\mathrm{t}}, \mathrm{V}_{\mathrm{t}}: \mathrm{ii} d\left(0, \sigma_{v}^{2}\right)$ and $\mathrm{Z}_{\mathrm{t}}$ is stationary process

Test Statistic

$=\frac{1}{T^{2}} \sum_{t=1}^{r} \frac{S_{t}^{2}}{\sigma^{2}}$

\subsection{Hypothesis Test for KPSS}

- $\mathrm{H}_{0}$ : The series is stationary

- $\mathrm{H}_{1}$ : Series is non-stationary

Where $\mathrm{S}_{\mathrm{t}}=\sum_{j=1}^{t} \hat{w} j$ with $\mathrm{wj}=y_{\mathrm{t}}-\bar{y}$ and $\sigma_{\infty}^{2}$ is an estimator of the long run variance of 
$\mathrm{Z}_{\mathrm{t},} \sigma_{\infty}^{2}=\lim _{T \rightarrow \infty} T^{-1} \operatorname{Var}\left(\sum_{t=1}^{T} z_{t}\right) \ldots$

The null hypothesis of the test is $\mathrm{H}_{\mathbf{0}}: \sigma_{v}^{2}=0$ against the alternative hypothesis $\mathrm{H}_{1}: \sigma_{v}^{2} \neq 0$

Reject $\mathrm{H}_{\mathbf{0}}$ if the test statistic is greater than the asymptotic critical values.

\section{Data Analysis}

Visual Representation of the time plot

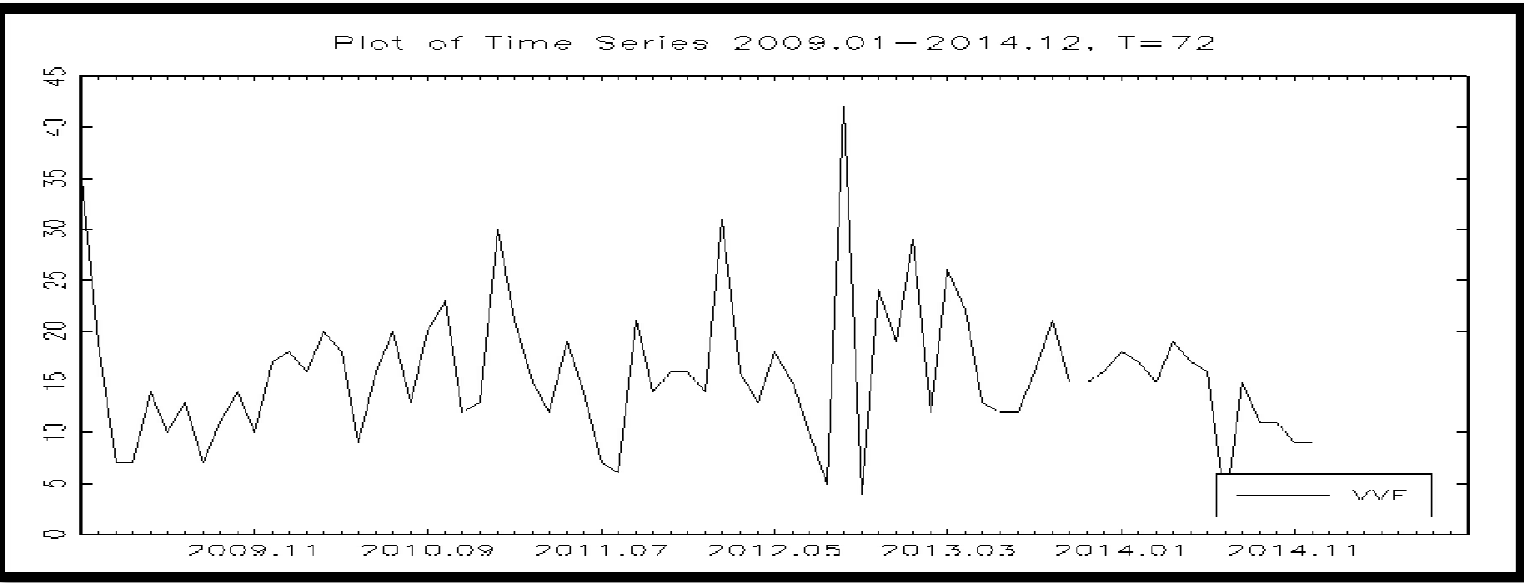

Figure 1: Time Series Plot of the Monthly Reported Cases of VVF in Kebbi State 2009-2014

The time series plot clearly shows the variability of the series appears to be changing with time and the mean and variance are not constant, suggesting that the series is not stationary.

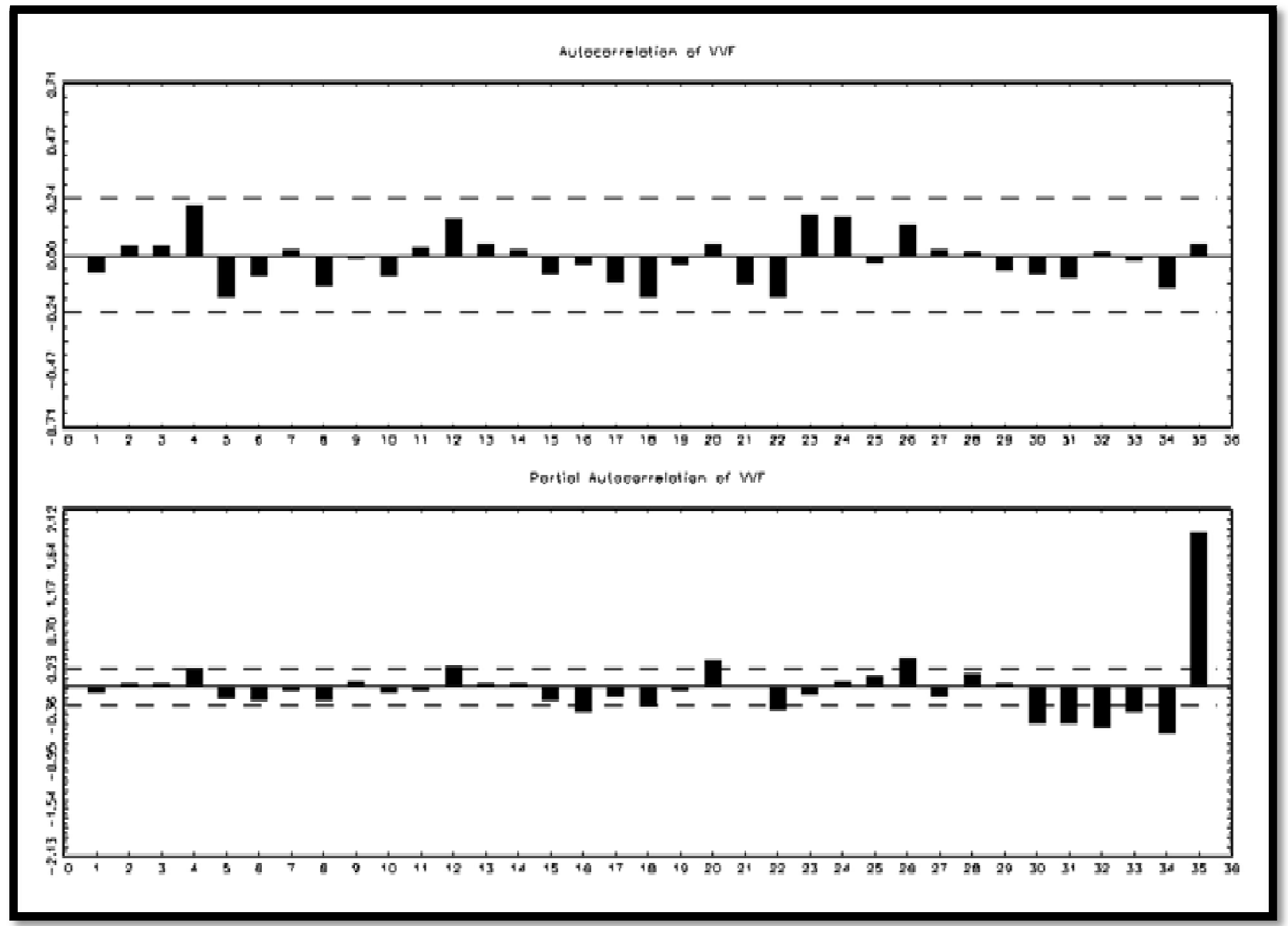

Figure 2: ACF and PACF of the VVF Series before differencing 
The plot of the ACF and PACF clearly shows that the mean and variance are not constant, suggesting that the series is not stationary.

\begin{tabular}{|c|c|c|c|c|}
\hline Variable & Mean & Min & Max & STD Dev. \\
\hline VVF & 15.70 & 3.00 & 42.00 & 16.85900 \\
\hline
\end{tabular}

Table 1

3.1. Augmented Dickey-Fuller (ADF) For VVF Test of Hypothesis

- $\mathrm{H}_{0}$ : The series has unit root

- $\mathrm{H}_{1}$ : The series is stationary

\begin{tabular}{|c|c|c|}
\hline $1 \%$ & $5 \%$ & $10 \%$ \\
\hline-3.43 & -2.86 & -2.57 \\
\hline
\end{tabular}

Table 2: Asymptotic Critical Values

\subsubsection{Value of Test Statistic: -4.2050}

The ADF test statistic is -4.2050 and the critical values at $1 \%, 5 \%$ and $10 \%$ are $-3.43,-2.86$ and -2.57 respectively shows that the test statistic is greater than all the critical values, if we take the absolute value, then there is no evidence to reject the null hypothesis that the series has unit root.

\subsection{Test of Hypothesis for KPSS Test}

- $\mathrm{H}_{0}: \sigma=0$ (The series is stationary)

- $\mathrm{H}_{1}: \sigma>0$ (Series is non-stationary)

KPSS test based on $\gamma(\mathrm{t})=\mathrm{a}+\mathrm{e}(\mathrm{t})$ (level stationary)

\begin{tabular}{|c|c|c|}
\hline $1 \%$ & $5 \%$ & $10 \%$ \\
\hline 0.347 & 0.463 & 0.739 \\
\hline
\end{tabular}

Table 3: Asymptotic Critical Values

\subsubsection{Value of Test Statistic: 0.839}

In this case the value of test statistic is 0.839 and the level of significance at $10 \%, 5 \%$ and $1 \%$ are $0.347,0.463$ and 0.739 respectively, which show that the test statistic is greater than all the critical values which indicated that there is no stationary in the series i.e. the series is not stationary.

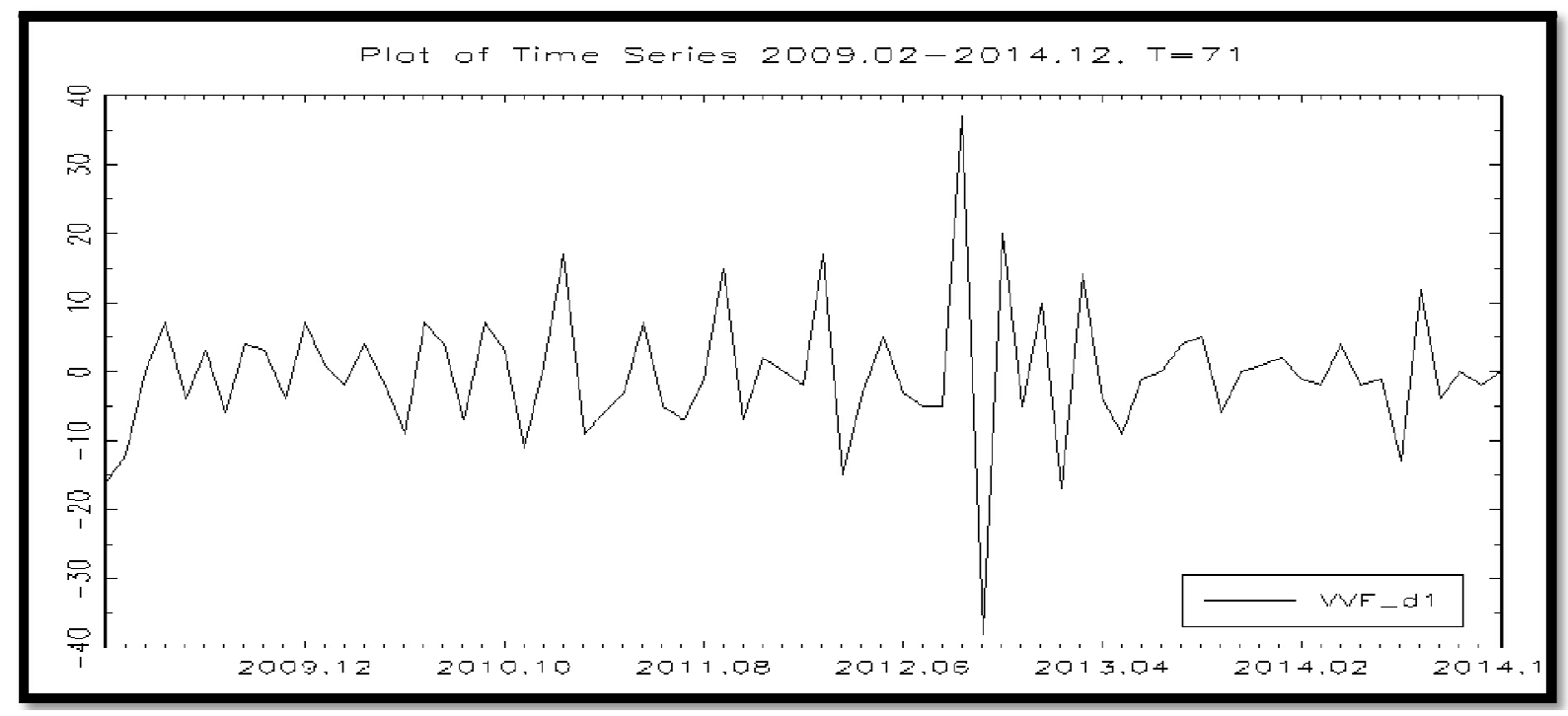

Figure 3: Plot VVF Series after the First Differenced

The plot clearly suggests that the mean and variance appeared to be constant. Therefore, the series is stationary since the mean and variance are constant. 


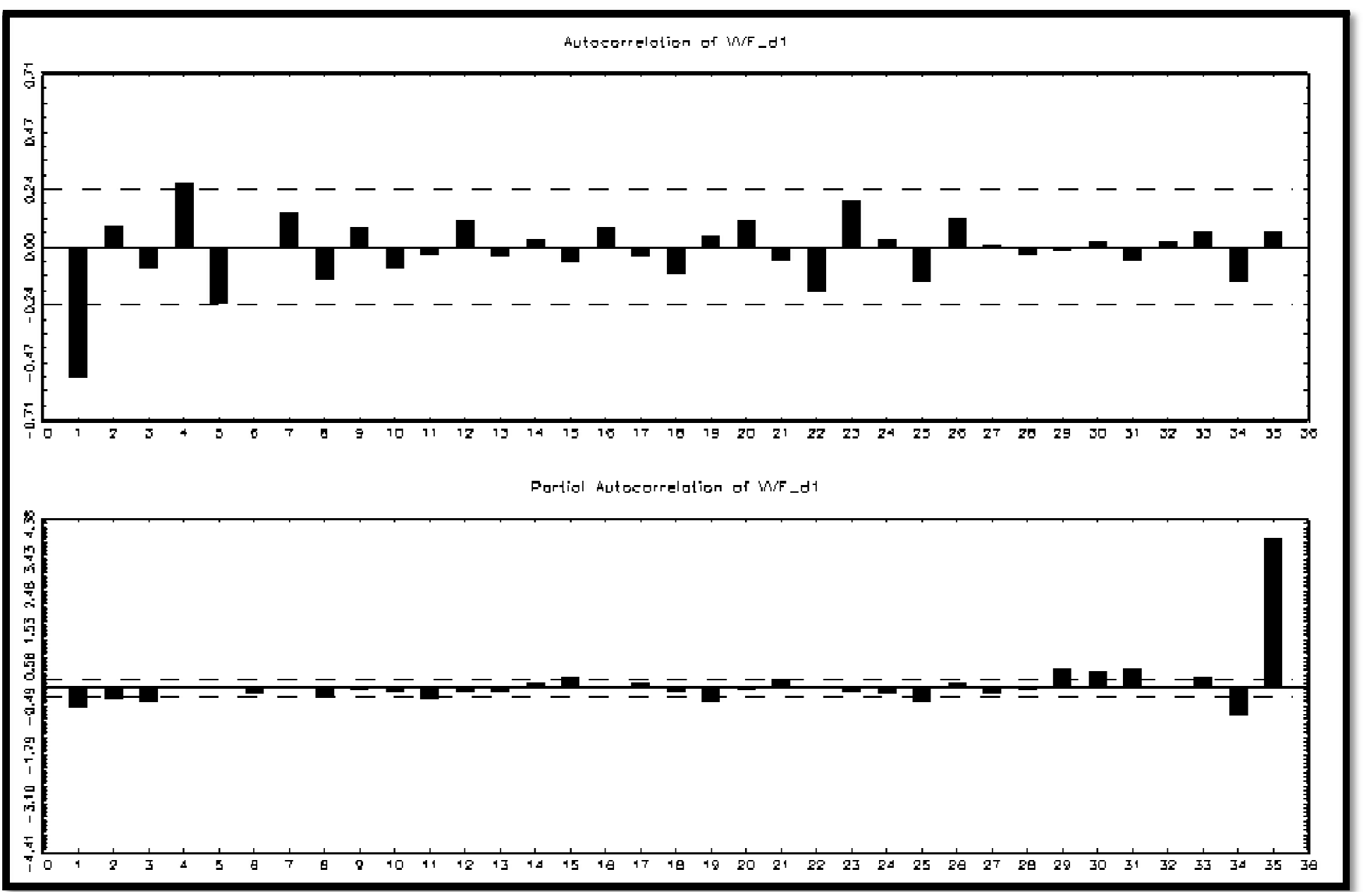

Figure 4: the ACF and PACF of First differencing of VVF cases in Kebbi State

$\mathrm{ACF}$ shows that there is no correlation function after the first differencing clearly indicating the series is stationary. The PACF shows that there is no correlation function after the first differencing and the series indicates the presence of AR and MA Process models.

\subsection{ODEL Identification}

To identify the best model, four models are chosen, $\operatorname{ARIMA}(0,1,0), \operatorname{ARIMA}(0,1,1)$, ARIMA $(1,1,0)$ and $\operatorname{ARIMA}(1,1$, 1). The autoregressive integrated moving Average of order ( $p, d, q)$, ARIMA ( $p, d, q)$ is use to choose the best model out of the four models so as to obtained which has the lowest AIC, (Akaike's Information Criterion), SBC (Schwarz Bayesian Criterion) and $\log$ likelihood Function.

\subsection{Estimation}

\begin{tabular}{|c|c|c|c|}
\hline MODEL & AIC & SBC & LOG \\
\hline ARIMA $(0,1,0)$ & 518.175643 & 520.424138 & -258.087821 \\
\hline ARIMA $(0,1,1)$ & 469.729177 & 476.226167 & -232.864588 \\
\hline ARIMA $(1,1,0)$ & 490.563904 & 495.060894 & -243.281952 \\
\hline ARIMA $(1,1,1)$ & 469.258777 & 474.004263 & -231.629389 \\
\hline
\end{tabular}

Table 4: Order of Estimation

ARIMA $(1,1,1)$ was chosen as our best model for the series, because it has the minimum AIC and SBC.

\subsection{Parameter Estimates of the Model}

Having identified the appropriate $\mathrm{p}, \mathrm{d}$ and $\mathrm{q}$ model the next stage is to estimate the parameters of the model. The minimum value of AIC (Akaike's Information Criterion), and SBC (Schwarz's Bayesian Criterion) may be regarded as the best fitted model. The result of the parameter estimates of the best model ARIMA $(1,1,1)$ are shown below: 
Sample range: $\quad$ [2009 M2, 2014 M12], $\mathrm{T}=70$

Model: ARIMA $(1,1,1)$

\subsubsection{Final Results}

Iterations until Convergence: 6

Log Likelihood -231.629389 Number of Residuals: 70

AIC : 469.258777 Error Variance : 44.777684717

SBC : 474.004263 Standard Error : $6.691613013 \mathrm{~s}$

DF: 67 Adj. SSE: 3586.305631941 SSE: 3377.479240268

\begin{tabular}{|l|l|l|l|l|}
\hline \multicolumn{7}{|c|}{ Dependent Variable: } \\
\hline & Coefficients & Std. Errors & T-Ratio & Approx. Prob \\
\hline AR1 & -0.22649715 & 0.13597582 & -1.66572 & 0.10044 \\
\hline MA1 & 0.82807142 & 0.09013984 & 9.18652 & 0.00000 \\
\hline CONST & -0.00094615 & 0.12246823 & -0.00773 & 0.99386 \\
\hline
\end{tabular}

Table 5

\subsection{Model Diagnosis}

Having chosen the best model, there is need to evaluate the adequacy of the estimated model or does the model fit the data? The following tests are being applied, which include:

PORTMANTEAU TEST: - This test is used to determine whether there is serial correlation in a time series.

The model is good if there is no serial correlation between the residual.

ARCH LM TEST: - This test for neglected conditional heteroskedasticity

(ARCH) the null hypothesis is that there is no conditional heteroskedasticity.

3.7. Portmanteau Test

(with 12 lags)

- $H_{O}$ : None of the Autocorrelation coefficients up to lags are different from Zero

- $H_{1}$ : At least one of the Autocorrelation coefficients up to lags is different from Zero

PORTMANTEAUTEST with 16 lags

Portmanteau: $\quad 11.8092$

P-Value (Chi^2): $\quad 0.3782$

Ljung\& Box: $\quad 13.5659$

P-Value (Chi^2): $\quad 0.2580$

\subsubsection{Decision Rule}

The null hypothesis is rejected for the portmanteaus test since the test statistics $11.8072>\mathrm{p}$-value 0.3782 and the alternative hypothesis is accepted, then, we conclude that at least one of the Autocorrelation coefficients up to lags are different from Zero.

ARCH-LM TEST (With 2 lags):

$H_{O}: \alpha_{O}=\alpha_{1}-----\alpha_{P}=0$ (The series has no ARCH effect)

$H_{1}: \alpha_{O} \neq \alpha_{1}-----\alpha_{P} \neq 0$ (At least coefficient is non-zero and we say the series has ARCH-LM effects)

ARCH-LM TEST with 4 lags:

Test statistic: $\quad 2.9973$

P-Value (Chi^2): 0.5583

F statistic: $\quad 0.7850$

P-Value (F): $\quad 0.5394$

Decision rule: The null hypothesis is accepted since the test statistic $2.9973>$ p-value $0.5583 a n d$ we conclude that the series has no ARCH-LM effect is present.

\subsubsection{Forecasting}

Forecast of future occurrence of VVF cases in Kebbi State from 2015-2016

Forecast range: [2015 M1, 2016 M12], T =24 


\begin{tabular}{|c|c|c|c|}
\hline TIME & LOWER CI & FORECAST & UPPER CI \\
\hline 2015 M1 & 1.9959 & 15.9116 & 29.8274 \\
\hline 2015 M2 & 1.7032 & 15.6309 & 29.5586 \\
\hline $2015 \mathrm{M} 3$ & 2.0780 & 16.0281 & 29.9781 \\
\hline 2015 M4 & 2.0519 & 16.0021 & 29.9523 \\
\hline 2015 M5 & 2.0807 & 16.0309 & 29.9812 \\
\hline 2015 M6 & 2.0840 & 16.0343 & 29.9845 \\
\hline 2015 M7 & 2.0914 & 16.0417 & 29.9919 \\
\hline 2015 M8 & 2.0973 & 16.0475 & 29.9977 \\
\hline 2015 M9 & 2.1034 & 16.0536 & 30.0038 \\
\hline 2015 M10 & 2.1094 & 16.0596 & 30.0099 \\
\hline 2015 M11 & 2.1154 & 16.0657 & 30.0159 \\
\hline 2015 M12 & 2.1215 & 16.0717 & 30.0219 \\
\hline 2016 M1 & 2.1275 & 16.0777 & 30.0280 \\
\hline 2016 M2 & 2.1335 & 16.0837 & 30.0340 \\
\hline 2016 M3 & 2.1395 & 16.0898 & 30.0400 \\
\hline 2016 M4 & 2.1456 & 16.0958 & 30.0460 \\
\hline 2016 M5 & 2.1516 & 16.1018 & 30.0521 \\
\hline $2016 \mathrm{M} 6$ & 2.1576 & 16.1079 & 30.0581 \\
\hline 2016 M7 & 2.1637 & 16.1139 & 30.0641 \\
\hline 2016 M8 & 2.1697 & 16.1199 & 30.0702 \\
\hline 2016 M9 & 2.1757 & 16.1260 & 30.0762 \\
\hline 2016 M10 & 2.1818 & 16.1320 & 30.0822 \\
\hline 2016 M11 & 2.1878 & 17.1380 & 30.0883 \\
\hline 2016 M12 & 2.1938 & 17.1440 & 30.0943 \\
\hline
\end{tabular}

The data above shows the rate at which the Vesico Vaginal cases will be in the next 24 Months in Kebbi State.

\section{Results and Discussion}

This paper examined the reported cases of VVF (Vesico Vaginal Fistula) between the period of 2009-2014 using the time series methodology (Box and Jenkins approach) the initial inspection of the time plot shown in Figure 1 that the cases of VVF in Kebbi state has seasonality pattern, the variability of the series appears to be changing with time, the mean and variance are not constant. Fig. (2a) and b shows the ACF and PACF indicate that there is no stationary in the series and there is need to attained stationary. The mean average number of WF cases is 15.70 as shown in Table 1 and the minimum number of people affected with VVF is 3 and the maximum number of people affected with the disease is 42 which indicate that the diseases is very rampant around September 2012 in kebbi state. Hence the data was transformed and some statistical test like ADF in Table 2 and KPSS in Table 3 is carried out to ascertain the stationary of the data. The initial test statistic value for ADF was -4.2050 is greater than all the critical values at $1 \%, 5 \%$, and $10 \%$ taken the absolute value which showed that the series has unit root, the same was observed for KPSS as shown in Table 3 where test statistic 0.839 is greater than all the critical values which indicate that there is no stationary in the series. However, after the transformation by taken the first differencing the series become stationary, as it shown in Figure 3, to confirm the stationary in the residual analysis the ACF and PACF was used in Fig.(4a) and b which shows there is no correlation function after the first differencing, clearly indicating that the series is stationary, ARCH-LM test and Portmanteau test are used to test if the series has serial correlation in residual, the test statistic for Portmanteau was 11.8092 and P-value was 0.3782 which showed that at least one of the autocorrelation is different from zero, while in case of ARCH-LM test, the test statistic was 2.9973 and P-value 0.5583 which showed that the series has no ARCH-LM effect is present. Table 4 is an order of estimation with 4 parameters was suggested i.e. ARIMA $(0,1,0)$, $\operatorname{ARIMA}(0,1,1), \operatorname{ARIMA}(1,1,0)$ and $\operatorname{ARIMA}(1,1,1)$, after the estimation the ARIMA $(1,1,1)$ model was found to be the best model that fit the data which has the minimum AIC and SBC. The result of the forecast showed that the menace of VVF in Kebbi state has increase in the next two years (Twenty four Months).

\section{Conclusion}

In this research, the developed model that best fit the data for Vesico vaginal Fistula in Kebbi state is found to be ARIMA $(1,1,1)$ and from the result of the forecast showed that there is increase in the rate of VVF in Kebbi State in the next two years (Twenty-four months), therefore there is need for Government and community interventions so as to reduce the menace. 


\section{References}

i. Ahmed,A. (2014) Seasonal effect on the prices of Sorghum in Bauchi State. Jewel Journal of Scientific Research (JJSR) 2(1), 49 - 54.

ii. Babayemi, A.W. and Olorunpomi, O. T. (2014). International Journal on model prediction of the reported cases of VVF in Kebbi State. www.Ijmsi.org// vol.2(12) 18-27.

iii. Box, G.E Jenkins, (1976). Time series Analysis forecasting and controls, sir Ronald John San Francisco, USA.

iv. Box, G.E.P, Jenkins, G.M and Reinsel, G.O (1998). Time series Analysis, Forecasting and control, 34ded, prentice tall, Englewood Cliff's.

v. Cook et al (2004) obstetric Fistula: the challenge to human right. International journal of Gynecology and obstetrics, 87, 72-77.

vi. Dickey, D.A \& W.A Fuller, (1997). Distribution of the Estimators Autoregressive Time series with unit root" Journal of the American statistical Association, 74, 427-431.

vii. Disk, Waal, D. and Armiya'u Y.D. (1993).The obstetric Fistula, A major public Health problems international Gynecology Journal 21 (4): 6-9.

viii. Hamilton, J.D. (1990). Seasonal integration and co integration, Journal of Econometric 4(8): 1-21.

ix. Harrison, K. A. (1989). Maternal Mortality in developing countries, British Journal of obstetrics and Gynecology 96(1): $1-3$.

x. http:/ / www.scholarsresearchlibrary.com/ archive.html

xi. Kwiatkowski, D, Phillips P.C.B Schmidt P and Shin. (1992.) Testing the null of Stationary against the alternative of unit root. Journal of Econometric Vol. 54, 159-178.

xii. M.A.Abdulazeez,A.Ahmed and F.W.Burari. (2010).The Use of Factorial Design in the Analysis of Global Solar Radiation in Nigeria. Archives of Applied Science Research.2(5),36-44.

xiii. Magashi, (2006) Female Genital Mutilation and our societies, retrieved from the web http:/ / www.nigeriamasterweb.com/ paperfrms.html.

xiv. Mayer, G. and Quinn, T. (1998). Forecasting Irish Inflation using ARIMA models Research paper, Department of research and publications central Bank of Ireland Dublin. 3 (10), 5-9.

xv. Metro (2004) Modification of O'Connor's techniques for the treatment of VVF repair described

xvi. Retrieved from the http:/ / www.medicalnewstoday.com/ medicalnews.php?newsid=40490

xvii. Tanko, N.M. (1998). Social cultural Factor and A etiology of Vesico Vaginal Fistula (VVF)" A paper presented at National Workshop at Liyafa palace Hotel Kastina on counselling of VVF patients.

xviii. Villey (2006). Incidence rate of WF after total abdominal hysterectomy (TAH)

xix. World Health Organization WHO (1997) communicating family planning in reproductive health Geneva(Available:http:/ / www.who.int/ reproductive-health/ publications/ fpp 